\title{
"The Multi-Faceted Kindergarten Teachers" \\ - A Multicultural Perception of Kindergarten \\ Teachers' Role in Light of the 'New Horizon' Reform
}

\author{
Eti Gilad (Corresponding author) \\ Department of Education \& Department of Educational Systems Management \\ Achva Academic College, Israel \\ E-mail: giladeti@012.net.il
}

Shosh Millet

M.Ed. programmes, Achva Education College, Israel

E-mail: millet@macam.ac.il

Received: February 19, 2015 Accepted: April 21, 2015 Published: May 7, 2015

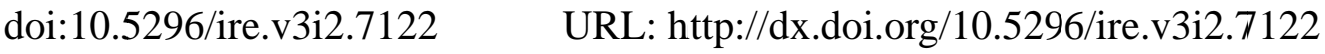

\begin{abstract}
This study aimed to expose the perception of kindergarten teachers' role from a multicultural aspect, following the 'New Horizon' reform, i.e. a systemic change which transpired during the last decade in Israeli kindergartens and schools. The study was conducted in a qualitative-interpretive approach and the research population comprised eight female kindergarten teachers, four Bedouin and four Jewish. The data were collected by a semi-structured interview. The research findings illustrate procedural changes in the perception of kindergarten teachers' role following the reform: from an organisational change through a pedagogical change and up to a leadership-oriented change. The contribution of the study resides in providing applied information which will constitute another layer in the development of education and professional development programmes for kindergarten teachers.
\end{abstract}

Keywords: organisational change, 'New Horizon' reform, perception of kindergarten teachers' role, multiculturalism 


\section{Introduction}

In Israel there is a separation between the kindergarten which absorbs children aged 3-6 years and elementary school where children learn from the $1^{\text {st }}-6^{\text {th }}$ grades. Similarly to schools, kindergartens have been undergoing dramatic changes in the recent decades as part of the reforms in society and the education system (Ballas, 2010; Ben-Peretz, 2011; Brandes \& Strauss, 2013; Chen, 2006; Fiersteter, 2012; Frish, 2012; Ministry of Education, 2013). One of the changes is re-defining the role of teachers and kindergarten teachers [hereunder "k-teachers"] so that they can cope with challenges and complexities which they have to face following the reforms. K-teachers are required to lead the kindergarten towards pedagogical growth and prepare the children for joining the school and society as value-oriented and intelligent people. That is, teach them the skills which would facilitate solving problems requiring effective thinking in order to develop the children as knowledgeable citizens capable of distinguishing between good and bad (Frish, 2012; Harrison \& Killion, 2007; Schleicher, 2012; Sergiovanni, 2002).

The research assumption is that a change in the k-teachers' role perception - from a kindergarten manager to a kindergarten leader with a vision who will lead the k-teachers themselves, the children and the kindergarten to pedagogical successes and facilitate their coping with the reform challenges. Hence, it is necessary to train the k-teachers to a management-leadership role.

The study investigated Jewish and Bedouin k-teachers' role perception as a result of the 'New Horizon' reform (Ministry of Education, 2009). Examining the role perception from a multicultural aspect will intensify the knowledge and its implementation when designing the policy of the k-teachers' education and professional development.

\section{Theoretical Background}

\subsection{Change in the Organisation}

In the last decades, far-reaching transformations have transpired in the education system both in the Israeli and global society. The globalisation, IT revolution, parents' role in the educational process of their children, pluralism and multiculturalism - all these and other transformations have impacted schools and kindergartens (Ballas, 2010; Ben-Peretz, 2011; Brandes \& Strauss, 2013; Chen, 2006; Cuban, 2006; Sarason, 1996). The social and technological change processes mentioned above are not manifested in a meaningful way in the kindergarten and entail the k-teachers" objections (Cuban, 2010; Eisner, 2010; Fullan, 2012). One of the systemic changes which was introduced in the Israeli education system during the last decade was the 'New Horizon' reform (Ministry of Education, 2009).

\subsection{The 'New Horizon' Reform}

'New Horizon' is a reform in the educational system designed to improve the quality of teaching, promote teacher-pupil relationship, increase the pupils' attainments and upgrade teachers' status (Ministry of Education, 2009). The reform underscores the professional development of educational practitioners, motivating the enhancement of the education system 
in Israel. The reform offers an important opportunity for improving the achievements of the education system by developing and institutionalising professional development processes of educational practitioners throughout their professional life (Knowles, 1989).

\section{3 'New Horizon' in Pre-Elementary Education}

One of the main goals of the 'New Horizon' reform in pre-elementary education is enhancement of the pedagogical and organisational processes which will improve the kindergarten activity as well as raise the quality of learning and the children's experience in it (Ministry of Education, 2012). Extending the school day facilitates examination and re-structuring of the role perception of the k-teachers and educational staff, the structure of teaching and learning in the kindergarten and the frameworks of structured and consistent professional development (Zimmerman \& Meyuchas, 2012). The k-teachers' role perception is the basis for their work in the kindergartenas leaders ofthechildren, staff and parents (Eisenberg, 2005; Zoran, 2005).

\subsection{K-teachers' Role Perception Following a Change}

The frequent and rapid changes which the kindergarten and its staff are experiencing under the leadership of the k-teachers affect the latter's role. Today theyare required to lead the kindergarten and deal with everything which this role involves (Klein \& Yablon, 2008). The role perception of the k-teachers who head the organisation is attributed new meanings. It highlights the way the k-teachers perceive the kindergarten as an autonomous organisation which decentralise authorities (Crowther, 2011; David Yellin College, 2012; Frank, 2013; Tal, 2012). The k-teachers heading the kindergarten face systemic changes in the role perception, kindergarten management, dialogue with the parents and mainly in the educational practice which is adjusted to children and shapes their image and identity as young learners. Consequently, the pre-elementary education system is required to create the optimal conditions for best development of the children and for their integration in innovative educational frameworks which are in line with the important transformations in education and in society (Ministry of Education, 2011, 2013).

\subsection{Multiculturalism}

Education for multiculturalism has been developing on the background of the debate about socialisation and absorption of social and cultural groups which are different from the hegemonic group in the country. The call to allow all ethnic-cultural voices to be heard in society is increasingly expanding (Greene, 1993; McElroy-Johnson, 1993; Yona, 2011; Yona \& Shenhav, 2005). The multicultural perception permeated schools and kindergartens and they started developing an awareness of it (Cummins, 1996).

Schools and kindergartens in Israel are a reflection of the multicultural society that consists of Jews (75\%), Arabs (21\%) and others (4\%) out of the total population of 8,107,000 citizens. The Jewish population is divided into orthodox Jews (about 20\%) and secular Jews (approximately 80\%). The Arab population is divided mainly into Christians, Muslims, Druze and Bedouins. The Bedouins are considered the most conservative in the Arab society and this is manifested by the tradition, customs and perception of women's role and status. On the other hand, the Bedouin society is affected by the encounter of Jews and other Arabs in Israel and by the 
western culture and it has been undergoing changes in all areas of life. The Bedouin society acknowledges that education is the key to life (Central Bureau of Statistics, 2013).

\subsection{Arab and Bedouin Education in Israel}

Education in the Arab sector has undergone changes since the establishment of the state. There has been a gradual increase in the number of learners in kindergartens, schools and higher education institutions. The number of school pupils increased from 22\% in 2001 to $27 \%$ in 2012 (Central Bureau of Statistics, 2013). Moreover, the number of female pupils in the Arab education system is increasingly growing as well as the number of female students in higher education institutions (Abu-Saad, 2006; Pessate-Schubert, 2003; Zeydan, Alian, \& Thorn, 2007). Most of the Bedouin women who want to acquire an academic degree choose to study in teacher education colleges, seeing themselves as future teachers in the education system in their area of residence. They view the teaching profession as leverage for personal and social transformations (Pessate-Schubert, 2005). These women expect the changes and understand their power but generally speaking they still conduct themselves according to the traditional codes and norms (Gilad, 2007).

\section{Research Question}

How do k-teachers perceive their role in a multicultural aspect following, the 'New Horizon' reform?

\section{Methodology}

\subsection{Research Methodology}

This study forms part of a comprehensive research conducted in a qualitative-interpretive approach and constitutes a case study. One of the most important advantages of a case study is its ability to offer insights about occurrences in the actual contexts and sites where they take place. Data collected from the participants can in fact seem insufficient but can definitely facilitate an understanding of what a small group thinks and feels as well as what are the group members' attitudes and approaches (Shkedi, 2012).

\subsection{Research Population}

The research population consisted of eight female k-teachers holding a B.Ed. degree. Four $\mathrm{k}$-teachers are Bedouin and four are Jewish, three secular and one orthodox. All of them live in the south of Israel and work in different kindergartens. They have a seniority of 8-22 years and worked in the education system within the framework of 'New Horizon' during the last four years. All of them work with children aged 5-6 attending a compulsory state-operated kindergarten. The participants were chosen out of the list of k-teachers working at the south of Israel according to the profile determined for the study. They were informed that the interview with them was for the research purposes only and would be anonymous.

\subsection{Research Tools}

The data were collected by means of a background details questionnaire and a semi-structured interview. The background details questionnaire was administered first in 
order to make a general initial acquaintance with the participants. It comprised items such as: age, teaching seniority, education, number of children in the kindergarten. At the second stage the interview was conducted, during which the following questions were asked: What were the changes in the job perception which transpired following the 'New Horizon' reform? Which changes were made in the order of daily activities in the kindergarten? In the interaction with the children? With the educational staff of the kindergarten? With the parents? The interview questions were based on a study conducted by Millet and Gillad (2014).

\subsection{Data Processing}

The interviews were content analysed. The categories were defined on the basis of previous studies which had investigated role perceptions (ETIC) and the collected data (EMIC) (Sabar Ben-Yehoshua, 1990). The categories were determined based on the data which were recurrent in all the interviews. For example, changes from the organisational, pedagogical and personal-cultural aspects. The categories were accepted after an agreement of at least $67 \%$ between the researchers. The analysis was performed at the following levels: the single interview level, ethnic-cultural group level and collective (all the k-teachers) level (Shkedi, 2012).

\subsection{Ethical Considerations}

The researchers followed the rules of ethics prevalent in Israel and protected the participants' rights. The participants were in-service k-teachers who learned in the college where this study was conducted and they gave their consent to participate in this study. The participants were told that the information collected through the questionnaires and a semi-structured interview was for the purpose of this study only. It is anonymous, confidential and no other use will be made of it.

\section{Findings}

The research findings illustrate that the 'New Horizon' reform entailed changes in the role perception of all the k-teachers. The change occurred in three stages. The first stage constituted a change in the organisational aspect, the second stage a change transpired in the pedagogical aspect and in the third stage a changeoccurred in the leadership aspect.

\subsection{First Stage - Changes in the Organisational Aspect - "The k-teachers Are Drowning in a Sea of Tasks"}

The k-teachers pointed out that the first change they had undergone following the reform was in the organisational aspect and mainly after a raise in wages and greater workload.

\section{Increased wages and longer work day}

All the k-teachers expressed their satisfaction with the increased wages as a result of the reform. However, they realised that this raise obliged them to work longer hours, from 30 to 41 hours per week. The Jewish k-teachers maintain that the additional work hours do not considerably enhance their practice as k-teachers.

A Bedouin k-teacher said: "I was glad to get higher monthly wages in spite of the additional 
work because the wages prior to the reform were low and inappropriate". A Jewish kindergarten voiced her dissatisfaction with the extension of the work day: "Despite the increase in wages, I don't think that they had to add 11weekly hours. I think that the work is demanding and does not end when I leave thekindergarten".

\section{$\underline{\text { A heavy workload }}$}

All the Jewish k-teachers and one Bedouin k-teacher argued that the reform created a heavy workload whereas three Bedouin k-teachers did not complain about the workload following the reform. As a result of the considerable change in the organisational aspect, the k-teachers were required to comply with new standards and a set timetable for documenting the various kindergarten activities and reporting them daily to the parents, educational staff and the inspectorate. One Jewish k-teacher pointed out: "The documentation is a burden for me. I am drowning in a sea of tasks which in my opinion do not promote me".

4.2 Second Stage - Changes in the Pedagogical Aspect - "The k-teachers Are Advancing on the Way towards the Change"

The organisational change brought about a pedagogical change mainly in the perception of pre-determining individual hours, pedagogical curriculum and core subjects integration. It also developed an empowering dialogue with the children, the staff and the parents.

\section{Individual hours}

All the k-teachers expressed a high degree of satisfaction with the additional individual hours which were built in the lessons plan following the reform. A Jewish k-teacher told: "Following 'New Horizon' I have more opportunities for meeting pupils individually in order to promote them in the studies and tighten the individual relationship with them. A Bedouin k-teacher indicated: "Following the 'New Horizon' reform, I am required to meet two children every day and I reach every boy and girl. I get to know them very well and can help them according to their own needs".

\section{Work plan and core subjects integration}

The k-teachers pointed out that they built a yearly work plan like in the past. The reform obliged them to change the plan in accordance with the core subjects and mostly to design activities based on the children's individual needs. A Jewish k-teacher specified: "I match the activities to the children's competences more than in the past". A Bedouin k-teacher added: "I make a yearly and pedagogical work plan which includes the core learning subjects combined with activities matching the development of the kindergarten children".

\section{Dialogue with the children, staff and parents}

One of the meaningful changes generated after the reform was incorporating in the work timetable the individual talks with the pupils, kindergarten staff and parents. This created structured meetings which were scheduled in advance. A Bedouin k-teacher explained: "I set communication channels and work procedures and hold staff meetings. This work format establishes better professional relations among the staff members". A Jewish k-teacher 
mentioned: "Today more than in the past I am required to establish communication and mutual relationships between the kindergarten staff and the parents. Eventually we can see a positive change in the relations with the parents".

\subsection{Third Stage - Changes in the Leadership-Oriented Aspect - "The k-teachers Are Stepping up and Looking towards a New Horizon"}

The organisational and pedagogical change resulted in a leadership-oriented change. Following the reform, k-teachers are more self-confident and delegate authorities from a place of personal and professional development.

\section{$\underline{\text { K-teachers' autonomy }}$}

A Jewish k-teacher said: "There is a stronger feeling of autonomy and trust in me on behalf of the system as the kindergarten manager. I am more independent in choosing the contents which are suitable to every child". A Bedouink-teacher mentioned: "The reform entailed a positive atmosphere for making decisions about learning subjects and teaching methods as well as about working methods with the children".

\section{Delegating authorities}

A Bedouin k-teacher reported: "The reform enabled an improvement in the planning and management of the kindergarten". A Jewish k-teacher added: "Before the reform I was like a chauffeur driving a group of travellers and today I am like a tour guide. I show them new places, explain and join them until we arrive to the desired destiny, i.e. allocating new roles and delegating authorities".

\section{Professional development}

A Bedouin k-teacher claimed: "New Horizon strengthens the profession and teaching quality by means of interesting in-service training courses which benefit my work in the kindergarten". A Jewish k-teacher added: "For 60 yearly hours I am studying topics of management and leadership. The level of the in-service training course is high. It promotes me up the hierarchy echelon and of course gives me many tools and competences".

\subsection{Cultural Aspect: Bedouin and Jewish k-teachers}

The Bedouin k-teachers adopted the reform without any considerable objections. They considered the reform as a source of personal and professional empowerment in the eyes of the family and the Bedouin society. The increased wages and changes in their work conditions legitimised for them economic and role stability. A Bedouin

k-teacherargued: "I feel that my family is proud of me, of my profession, wages and status. In the village where I live people respect me following the transpired changes". Unlike them, the Jewish k-teachers do not indicate the issue of professional status in the eyes of the family and the society. Moreover, they do not consider that the wages are a stable source of income like the Bedouin k-teachers. As one of the Jewish k-teachers said: "For me the wages necessitate much additional work which does not justify the halo surrounding the reform".

Regarding the education for multiculturalism, all the k-teachers referred to changes in the 
valued perceptions as an inherent feature of the 'New Horizon' reform which underscores the education of individuals as part of a multicultural society. The Bedouin k-teachers aspire to achieve particular education which engages in the Bedouin tradition and heritage in parallel to equalitarian education, humanistic education and social justice. This view was also expressed by an orthodox Jewish k-teacher. The three other Jewish k-teachers related to education for multiculturalism as a dialogue which gives room to many opinions even if they are contradictory from a cultural point of view. As one Bedouin k-teacher claimed: "We should highlight the history of the Bedouins, their uniqueness in the Arab society, teach the Bedouin culture through stories, songs and fables". A Jewish k-teacher pointed out: "During my meetings with children in the kindergarten I allow an open and critical dialogue whereby the children voice their different opinions while emphasising the importance of accepting the different and respecting every person".

\section{Discussion and Summary}

The main research aim was to explore the k-teachers' role perception from a multicultural aspect in light of the 'New Horizon' reform. This reform constitutes an essential opportunity for restructuring the k-teachers' role perception.

The research findings illustrate that the 'New Horizon' reform opened a gate for changing the k-teachers' role perception in the organisational, pedagogical and leadership-oriented aspects among the two cultural groups - Jewish and Bedouin. The findings highlight the three stages in the k-teachers' professional and personal development. There is a salient procedural development pattern from the organisational practice stage through the pedagogical practice stage and up to advancing towards the leadership practice stage.

In the organisational aspect, the k-teachers and mainly the Bedouin ones saw themselves involved in organisational processes and dedicated their time and skills to these processes. This finding is in line with Gavish and Friedman (2007) who argued that teachers as organisers should first and foremost have organisational knowledge and they are expected to be managers and leaders at school. The Jewish k-teachers objected particularly to the organisational aspect associated with longer school days and the burden of documenting and reporting about the kindergarten activities. This objection stemmed from discontinuation of familiar and safe work patterns. Oplatka (2010) elucidates that the objection to the change results from uncertainty, misunderstanding of the meaning of the change and undermining the fixed and known equilibrium. According to Hadad Ma-Yafit (2010), extending the school day allows examination and re-structuring of the role perception of k-teachers and educational staff. However, in practice, not all the Jewish k-teachers were pleased with the longer school day. They argued that they were working hours beyond the formal school day and in their opinion the scope of hours would not lead to a change in their job perception.

In the pedagogical aspect, all the k-teachers indicated the individual hours as a positive change and an empowering element in their role perception. They consider that the individual talks with the children and the meetings with the kindergarten staff are an essential tool and quality time for educational practice and promotion of the children. This finding is supported by other researchers (Hadad Ma-Yafit, 2010; Moss \& Urban, 2010). 
In the leadership-oriented aspect, among the variety of leadership components, autonomy, delegation of authorities and professional development were prominentin this study. According to the k-teachers, the reform increased their sense of autonomy. They admitted it did exist in the past but today it was enhanced and became a positive transformation. This finding complies with one of the reform goals, namely educate autonomous k-teachers who are capable of analysing complex situations and making the appropriate decisions (Ministry of Education, 2009).

This goal is set down in the democratic-humanistic concept which views individuals as autonomous personalities who shape their world and are responsible for their growth (Aloni, 2013). The k-teachers' wish to delegate authority matches the decentralised leadership approach which advocates the need and importance of decentralising authorities and involving the teachers in the school leadership (Crowther, 2011; Crowther, Ferguson, \& Hann, 2009; Frank, 2013) and the wish not to lead the kindergarten alone (Firsteter, 2010).

In the cultural aspect, no significant differences were found in the k-teachers' role perception after the reform. The only difference was manifested by the Bedouin k-teachers who believed the reform was an opportunity for improving their status in the Bedouin family and society. The increased wages and better work conditions affected their self-image in their eyes and in the eyes of society. This finding is in line with the findings of Millet and Gilad (2014) regarding role perception in the Bedouin society as well as the development of women's education in the Bedouin society as part of the Arab society. They see the teaching profession as leverage for personal and social changes as part of the insight that education is the key to success in life (Abu-Saad, 2006; Pessate-Schubert, 2005; Zeydan, Alian, \& Thorn, 2007).

In the aspect of education for multiculturalism, all the k-teachers emphasised the importance of implementing humanistic and social values in the teaching processes and kindergarten management. Education for multiculturalism enables a dialogue of respect between people and mutual enrichment based on openness to the other and at the same time getting to know the self. This is done by expanding acquaintance with the ethnic-cultural heritage of the group, nurturing cultural identity and raising self-confidence (Banks, 1995; Klein, 1993; Yona, 2011; Yona \& Shenhav, 2005). The findings are supported by the research literature dealing with the topic of education for multiculturalism, emphasising one of the goals of education in Israel, namely accepting the other and living in an equalitarian society (Greene, 1993; McElroy-Johnson, 1993; Yona, 2011; Yona \& Shenhav, 2005).

This study has two salient contexts of education and in-service training courses. The first context is related to the k-teachers' role perception in an age of reforms and transformations and the second is associated with the k-teachers' role perception in a multicultural and leadership-oriented aspect. Knowledge about the k-teachers' role perception will entail development of education programmes and high quality professional in-service training courses. These programmes will encompass elements of k-teacher-leader development with an emphasis on humanistic values and acceptance of others. The study recommends conducting further studies of k-teachers education and professional development programmes 
from a multicultural aspect.

\section{References}

Abu-Saad, I. (2006). Palestinian education in Israel: The legacy of the military government. Holy Land Studies: A Multidisciplinary Journal, 5(1), 21-56. http://dx.doi.org/10.3366/hls.2006.0001

Aloni, N. (2013). Good education: Towards life of discipline, justice and self-actualisation. Tel Aviv: Hakibbutz Hameuchad Publishing and MOFET Institute. [Hebrew]

Ballas, N. (2010). Trends in the development of the education system. In D. Ben-David (Ed.), Report of the state of the country, society, economy and policy (pp. 203-245). Jerusalem: Taub Centre. [Hebrew]

Banks, J. A. (1995). The canon debate knowledge construction and multicultural education multicultural education. In J. A. Banks \& A. M. Banks (Eds.), Multicultural Education, Transformative Knowledge and Action (pp. 3-29). NY: Teachers Press.

Ben-Peretz, M. (2011). Shaping an educational policy - A holistic approach as a response to global changes. Tel Aviv: MOFET Institute. [Hebrew]

Brandes, O., \& Strauss, O. (Eds.). (2013). Education for a society of culture aknowledge: Transformations in the $21^{\text {st }}$ century and their implications - Recommendations for adapting the education system in Israel to the $21^{\text {st }}$ century. Jerusalem: The Initiative for applied research in education, Israeli National Academy of Science. [Hebrew]

Central Bureau of Statistics (2013). Population: according to population groups. Israel Statistical Report, 64. Jerusalem: Central Bureau of Statistics. [Hebrew]

Chen, D. (2006). Between vision and logic: On change and innovation strategies in Education. In D. Chen (Ed.), Experimental schools: the manufacture of innovation in education (pp. 11-39). Tel Aviv: Tel Aviv University, Ramot Publishing. [Hebrew]

Crowther, F. (2011). From School Improvement to Sustained Capacity: The Parallel Leadership Pathway. Foreword by Andy Hargreaves. Corwin Press.

Crowther, F., Ferguson, M., \& Hann, L.(2009). Developing teacher leaders: How teacher leadership enhances school success (2nd ed.). Thousand Oaks, CA: Corwin Press.

Cuban, L. (2006). International and historical viewpoints about national educational reforms. In D. Inbar (Ed.), Towards an educational revolution (pp. 22-34). Jerusalem: Van-Leer Institute and Hakibbutz Hameuchad Publishing. [Hebrew]

Cuban, L. (2010). The reform returns again and again. In G. Fisher \& N. Michaeli (Eds.), Change and improvement in education systems. An anthology of articles (pp. 24-50). Jerusalem: Branco Weiss Institute and Avney Rosha Institute. [Hebrew]

Cummins, J. (1996). Negotiating Identities: Education for Empowerment in a Diverse Society. Ontario, CA: California Association for Bilingual Education. 


\section{Macrothink Institute ${ }^{\text {tM }}$}

David Yellin College. (2012). The autonomy of kindergarten teachers in the age of New Horizon. The young age staff. MOFET Bulletin, 47, 13-29. [Hebrew]

Dayan, Y. (2008). Towards professionalism in early childhood practicum supervision a personal journey. European Early Childhood Education Research Journal, 16(2), 153-170. http://dx.doi.org/10.1080/13502930802141592

Eisenberg, M. (2005). Developmental stages and contextual factors which affect processes and experiences in the professional career of the kindergarten teacher in the first years. M.A. dissertation. Beer-Sheva: Ben-Gurion University of the Negev. [Hebrew]

Eisner, A. V. (2010). An educational and ecological reform of school education. In G. Fisher \& N. Michaeli (Eds.), Change and improvement in education systems. An anthology of articles. Jerusalem: Branco Weiss Institute and Avney Rocha Institute. [Hebrew]

Firsteter, A. (2012). Is it good for people to be alone? Kindergarten teachers' attitude towards their role as single educators in kindergartens for 5-year old children. Reflection and Research in Teacher Education, 13, 9-33. [Hebrew]

Frank, A. (2013). Leadership motivating to practice and involvement: Nine steps on the way from management to leadership. MOFET Bulletin, 51, 82-88. [Hebrew]

Frish, Y. (2012). The kindergarten teacher as a kindergarten manager and educational leader: Management chapters. Kiryat Shmuel: 'Shaanan' Orthodox Academic College. [Hebrew]

Fullan, M. (2012). Stratosphere: Integrating Technology, Pedagogy, and Change Knowledge. Toronto, Canada: Pearson, Canada.

Gavish, B., \& Friedman, I. (2007). The teacher as an organisational person: Contribution of the work environment perceived by the teacher as predictor of burnout at the beginning of the first year of teaching and at its end. Reflections in Management and Organisation of Education, 29, 55-87. [Hebrew]

Gilad, E. (2007). Gender in teacher education. In E. Gilad \& L. Baratz (Eds.), My voice your voice - Gender and social aspects. Israel: Achva Academic College. [Hebrew]

Greene, M. (1993). The passions of pluralism: multiculturalism and the expanding community. Educational Researcher, 22(1), 13-18. http://dx.doi.org/10.2307/1177301

Hadad Ma-Yafit, S. (2010). Letter to the Kindergarten Teachers, 29.5.11. Jerusalem: Ministry of Education. [Hebrew]

Harrison, C., \& Killion, J. (2007). Ten Roles for Teacher Leaders. Educational Leadership, 65(1), 74-77.

Klein, G. (1993). Introduction to Education: Education towards race equality (pp. 51-60). London: Cassell. 


\section{Macrothink

Klein, P., \& Yablon, Y. (2008). From research to practice in young age education. Jerusalem: Committee for the Examination of Education for Young Age Methods and the Israeli National Academy of Science. [Hebrew]

Knowles, M. (1989). The Making of an Adult Educator. San Francisco: Jossey\&Bass.

McElroy-Johnson, B. (1993). Giving voice to the voiceless. Harvard Educational Review, 63(1), 85-104.

Millet, S., \& Gilad, E. (2014). A multicultural view of mathematics male teachers at Israeli elementary school. In D. Patkin \& A. Gazit (Eds.), The narrative of mathematics teachers: Features of education, knowledge, teaching and personality of elementary school mathematics teachers (pp. 262-292). Tel Aviv: MOFET Institute. [Hebrew]

Ministry of Education (2009). New Horizon - Policy outline for professional development of educational practitioners. Jerusalem: Ministry of Education, Administration of Education, In-Service Education Courses and Educational-Social Equality Promotion. Retrieved from http://cms.education.gov.il/educationcms/units/staj [Hebrew]

Ministry of Education (2011). A kit for planning, management and organisations towards the 2012 school year for kindergarten teachers and the pedagogical administration inspectors. Jerusalem: Ministry of Education. [Hebrew]

Ministry of Education (2012). 'New Horizon' reform inkindergartens. Available online: http://cms.education.gov.il/EducationCMS/Units/Ofek

Ministry of Education. (2013). Educational practice in kindergartens: Guidelines for the educational staff. Jerusalem: Ministry of Education, Pedagogical Administration, Department of Pre-Elementary Education, Publications Section. [Hebrew]

Moss, P., \& Urban, M. (2010). Democracy and Experimentation; two fundamental values for education. Guetersloh: Bertelsmann Stiftung.

Oplatka, I. (2010). Teachers and head teachers in New Horizon: From objection to participation. Hed Hachinuch, 3(85), 18-30. [Hebrew]

Pessate-Schubert, A. (2003). Changing from the Margins: Bedouin Women and Higher Education in Israel. Women's Studies International Forum, 4(26), 285-298. http://dx.doi.org/10.1016/S0277-5395(03)00076-1

Pessate-Schubert, A. (2005). I go out and as if I am touching the world, seeing things more clearly: women, higher education and the Bedouin society in the Negev. Megamot, 43(4), 659-681. [Hebrew]

Sabar Ben-Yehoshua, N. (1990). The qualitative research in teaching and learning. Ben-Shemen: Modan Publishing House. [Hebrew]

Sarason, S. B. (1996). Revisiting 'The Culture of the School and the Problem of Change'. New York: Teachers College Press. 
Schleicher, A. (2012). Preparing Teachers and Developing School Leaders forth 21st Century: Lessons from around the World. OECD Publishing.

Sergiovanni, T. J. (2002). Managing a school: Theoretical and practical aspects. Tel Aviv: Open University.

Shkedi, A. (2012).The meaning behind the words, chapters 4-5. Tel Aviv: Ramot Publishing. [Hebrew]

Tal, K. (2012). Emphasising the importance of young age education at the beginning of the $21^{\text {st }}$ century: Opportunities, risks and dilemmas. MOFET Bulletin, 47, 25-31.

Yonah, Y. (2011). Renewed thinking: Multiculturalism in separate spaces and in common spaces. Conference of the Society for the Study of Jewish Education in Israel and abroad. Israel: Achva College of Education. [Hebrew]

Yonah, Y., \& Shenhav, Y. (2005). What is multiculturalism? On politics of differentiation in Israel. Tel Aviv: Bavel Publishing House. [Hebrew]

Zeydan, R., Alian, S., \& Thorn, Z. (2007). Motives for choosing the teaching profession among pre-service teachers in the Arab sector. Dapim, 44, 123-143. [Hebrew]

Zimmerman, H., \& Meyuchas, A. (2012). New Horizon in kindergartens in teacher education colleges. MOFET Bulletin, 47, 20-14. [Hebrew]

Zoran, N. (2005). Curriculum at young age - aspects of educational planning. Ph.D. Thesis. Haifa: University of Haifa. [Hebrew]

\section{Copyright Disclaimer}

Copyright reserved by the authors.

This article is an open-access article distributed under the terms and conditions of the Creative Commons Attribution license (http://creativecommons.org/licenses/by/3.0/). 